\title{
THE FEEDING AND CONDITION OF PLAICE LARVAE IN GOOD AND BAD PLANKTON PATCHES
}

\author{
By J. E. SheLbourne \\ Fisheries Laboratory, Lowestoft \\ (Plate I and Text-figs. I-3)
}

In spite of the high fecundity of many food-fish species, only a minute proportion of the total eggs spawned enter the fishery later on, as marketable adults. This principle is not in dispute. There is, however, a considerable division of opinion among fisheries biologists on the general shape of the mortality curve. Hjort (1914, 1926) suggested that the final size of a year-class of cod and herring is determined shortly after hatching, and is related to the larval food supply and drift. Sund (1924) supported this view. Johansen (1927) investigated yearly fluctuations in the abundance of fish larvae in Danish waters, and came to the conclusion ' ....that in cold winters, when there is a relatively marked outflow of comparatively fresh water from the Baltic, through the Belts and Southern Kattegat, the tiny plaice larvae fail to obtain sufficient nourishment and die of starvation en masse'. Rollefsen (1930) demonstrated the lethal effect of agitation on the vulnerable stages of the cod egg, and thought that wave action during incubation might strongly influence the early slope of the mortality curve. The observations of Soleim (1940, I942) on herring larvae off the coast of Norway, and in the laboratory, led him to infer a critical starvation period following yolk resorption.

The reality, or otherwise, of a critical period in the early life history of marine fishes has recently been discussed by Marr (1956) using two sets of data; those of Sette (1943) on the Atlantic mackerel (Scomber scombrus) and of Sette \& Ahlstrom (I948) and Ahlstrom (1954) on the Pacific sardine (Sardinops caerulea) of North America. Marr interpreted the Atlantic mackerel data as having a relatively constant survival rate with a brief high mortality at the age of 30-40 days, but no critical period at the time of yolk resorption. Although the Pacific sardine records show an apparent critical phase, Marr contested the reality of this result on the basis of inadequate sampling of the very young larval population.

As a complement to the studies of Simpson (I95I) on the fecundity of North Sea plaice (Pleuronectes platessa) and the distribution of its eggs and larvae (in press), preliminary attempts were made during the 1955 spawning season, to follow the fate of plaice egg broods during their early life history. Bad 
weather limited activities, but some significant observations were made on the condition of plaice larvae in good and bad feeding conditions, relevant to the unsolved problem of early mortalities.

\section{SAMPLING TECHNIQUE}

The spawning season of the North Sea plaice lasts from late December until late March, with the peak of egg production occurring round about the end of January. The spawning area extends from the Straits of Dover to the southeast edge of the Dogger Bank and round into the Heligoland Bight (Textfig. I). There are two centres of maximum production: in the south, over the

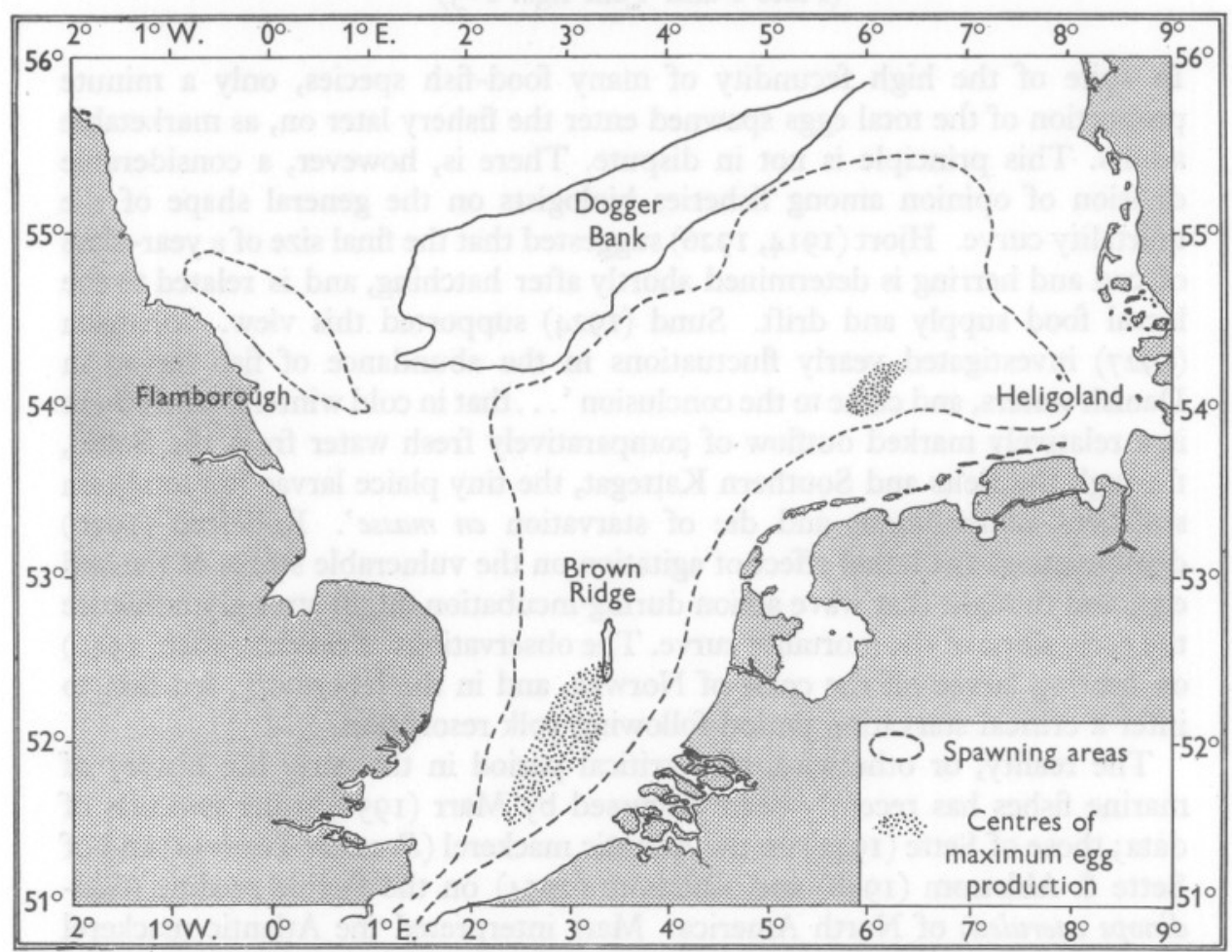

Text-fig. I. Plaice spawning grounds in the southern North Sea.

Brown Ridge, and in the north-east, off Heligoland. The Southern Bight spawning ground covers an area of some 8000 square miles; the Heligoland ground, some 2500 square miles. In addition, there is a minor spawning ground off Flamborough Head.

Marr (1956) has already stressed the importance of adequate coverage, in time and space, of spawning areas during mortality surveys, and criticizes the inference of Soleim (1942) regarding a critical phase, on these grounds. Plaice 
larvae from the Southern Bight drift in towards the Dutch and German coasts, parts of which are still mined. As winter weather interferes with plans for frequent surveys over such a large area of sea from a single research vessel, it was decided to attempt an intensive mortality study of the egg and larval population around a point marked by a floating radio buoy, rather than to assess the death-rate for the whole spawning area. The limitations of such a scheme were fully realized; in particular, the fact that the resultant mortality curve would not necessarily be typical for the whole area, even during the same period in time. Furthermore, it was not known whether a floating buoy, equipped with a 'tail' of sea drogues would continue to mark a pelagic plaice population in all weathers.

In late January 1955 , a Heligoland larva net of $\mathrm{I} \cdot 5 \mathrm{~m}$ diameter, with 60 meshes per inch silk, was used from R.V. Sir Lancelot south-west of the Brown Ridge, in search of an extensive patch of evenly scattered young plaice eggs. Such a patch was found, and a buoy, fitted with a short-range radio transmitter and a set of sea drogues, planted in the middle of it. By intensively sampling a close grid around the buoy in the middle of a big patch, it was hoped to overcome the problem set by differential water movement during gales, on the assumption that eggs and larvae moving out of grid range would be equally replaced.

Fair weather continued for a period of 12 days, during which time six grids of thirteen equally spaced stations per grid, were completed. Each grid covered an area of I square mile with the buoy as its centre. Two plankton hauls were made at each station, sampling after dusk to limit larval avoidance (Silliman, 1943; Bridger, 1956). Representative salinity samples and temperature records remained consistent throughout the I2-day period. Thereafter, strong south-westerly winds and a heavy swell shifted the buoy some 40 miles to the north-east in a week, and it was clear from the rapidly changing plaice egg population, supported by temperature and salinity records, that the buoy had moved off the original patch.

A second attempt was made in early March, and once again we were fortunate enough to have a I2-day period of tolerable weather. Another extensive patch of evenly distributed eggs and larvae was found south-west of the Brown Ridge, the buoy planted and a total of six grids completed before gales interfered with operations. In this case the grid had an extra station and covered an area of 5 square miles to give the ship plenty of room to manoeuvre into sampling positions during rough weather.

I do not intend to dwell at length on the difficulties attending this method of deriving a mortality curve. It is sufficient to say that in a shallow sea area, the chances of maintaining contact with the same fish brood throughout incubation and early larval development are not good. Differential water movements due to currents, tide and strong winds must have a profound effect on brood dispersion, rendering the study of diminishing numbers within a small body 
of water, an uncertain method of assessing mortality. A reasonable period of moderate weather is necessary for success.

Although these surveys failed to produce a mortality curve, they did focus attention on an anomalous situation very relevant to the death-rate of larval fish in the sea. There was a noticeable scarcity of plankton during the first series of grids in late January, coupled with generally poor larval condition and no indication of growth beyond the yolked stage. Plankton was abundant during the March grids; a good proportion of the larvae was robust and apparently advancing beyond the stage of final yolk loss. These differences made themselves felt during the cursory examination of plankton samples at sea. A more detailed study of formalin-preserved material was made in the laboratory.

\section{DEVELOPMENT STAGES OF THE PLAICE}

A plaice egg is provided with food, and its development rate during yolk utilization is, in normal circumstances, controlled by temperature (Apstein, 1909). Larval fish, on the other hand, may start taking food before the yolk is completely resorbed (Table 2). Experience in the laboratory suggests that the larval feeding rate affects the development rate at a given temperature. Thus, consistently successful feeders will reach metamorphosis long before their less voracious brethren in the same tank. Any attempt to assess the development rate of sea larvae without fore-knowledge of their feeding rates, must be very approximate. If the development rate varies from place to place in sea areas with patchy plankton, then it follows that over-all estimates of the early mortality rates must be similarly approximate.

Aurich (194I) produced a series of developmental stages for the plaice larva, based on the investigations of Dannevig (1897), Reibisch (1902) and Apstein (1909), which take into account the principal morphological changes between hatching and metamorphosis. Mr A. C. Simpson of this laboratory has amended Aurich's staging to give the following categories (P1. I, figs. I-5):

Stage I. Yolk still present.

2. Yolk resorbed but notochord still straight.

3. Eyes still symmetrically placed. Notochord bent.

4. Eye started to move, but not yet reached edge of head.

5. Eye on or over the edge of the head.

I have further subdivided stages $I$ and $\mathbf{2}$ as follows:

Stage I. Yolk-sac stage.

$(a-c)$ Divided into three categories according to the amount of yolk in the sac (indicated + ) and also to the degree of curling of the gut and extent of ventral mesectodermal fusion (Shelbourne, 1956). 
(d) A yolk spherule stage when the yolk has been reduced to a small sphere, usually located in the arch of the intestine.

2. (a) Early. The yolk completely resorbed but the distinctive cushion of tissue below the caudal axis not yet fully developed.

(b) Late. Caudal cushion distinct.

If food is scarce, the yolk spherule stage is succeeded by early stage $2(a)$ when all the yolk has disappeared. In good food conditions, however, larvae may start heavy feeding whilst yolk is still present. The drain on the yolk is then interrupted and a yolk spherule may be carried over to stage $2(b)$ when the caudal cushion is complete. For the purposes of this investigation, I prefer to regard stages $\mathrm{I}(d)$ and $2(a)$ as a transitional group, lying between the 'yolked' and 'non-yolked' larvae of previous development studies. If a truly 'critical period' does occur in the life history of a brood of fish, it is surely at this point, when yolk reserves are exhausted and the larvae have to rely on external food sources.

\section{COMPARATIVE ABUNDANCE OF PLANKTON}

After removal of the plaice fraction, the net hauls at five representative stations per grid were analysed for zoo- and phytoplankton, using the Stempel pipette technique. The results are presented in Table I. The estimates are to the nearest thousand after adjustment to an arbitrary total flowmeter reading of 200 revolutions per grid (40 rev./station). The species dealt with were

\section{TABLE 1. THE COMPARATIVE ABUNDANCE OF PLANKTON IN} THE JANUARY AND MARCH SAMPLES

\begin{tabular}{|c|c|c|c|c|c|c|c|c|c|c|}
\hline & & Zoop & kton & hou & ds) & & tople & kton & ous: & ds) \\
\hline Date & 宫 & 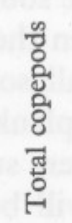 & 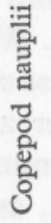 & 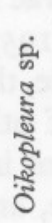 & 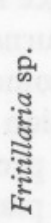 & 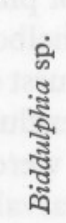 & $\begin{array}{r}\frac{5}{3} \\
\frac{\pi}{3} \\
\frac{\pi}{3}\end{array}$ & 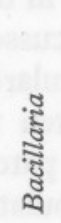 & 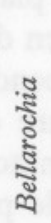 & 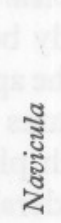 \\
\hline 20. i. 55 & I & 30 & - & - & - & - & - & - & 5 & - \\
\hline 2r.i. 55 & 2 & 43 & - & - & - & + & I & - & 4 & + \\
\hline 22. i. 55 & 3 & 36 & - & - & - & - & II & - & - & - \\
\hline 24. i. 55 & 4 & 63 & - & - & - & - & I & I & - & - \\
\hline 26. i. 55 & 5 & 36 & - & - & - & I & 4 & - & - & + \\
\hline I. ii. 55 & 6 & $2 I$ & - & + & + & I & + & - & - & - \\
\hline 8. iii. 55 & 7 & 66 & 2 & 6 & I & 49 & 4 & 7 & - & 5 \\
\hline Io. iii. 55 & 8 & 94 & 2 & 7 & I & 358 & 5 & 73 & 7 & 23 \\
\hline I6. iii. 55 & 9 & I93 & 4 & I0 & 4 & I539 & 48 & I82 & 24 & 297 \\
\hline I8. iii. 55 & Io & II 2 & + & 6 & 29 & 774 & - & $3 I$ & - & 603 \\
\hline 20. iii. 55 & II & I2I & + & 3 & + & 1070 & - & 57 & - & 255 \\
\hline 22. iii. 55 & 12 & I74 & 2 & 5 & + & 1678 & 2 & 15 & - & I74 \\
\hline
\end{tabular}

The numbers (to nearest thousand) are the total plankton counts for five representative stations on each grid, adjusted to a total flowmeter reading of 200 revs. $+=$ present in small numbers. 
common to both patches, but other diatoms were present in large numbers during the March cruises. The Heligoland larva net is not a quantitative sampling instrument for the smaller animals, e.g. copepod nauplii and very young appendicularians, nor for diatoms, but these organisms are caught in rough proportions to their abundance.

It is clear from Table I that over-wintering conditions prevailed in the first plankton patch. Adult copepods, too large to be used as food by plaice larvae, were fairly abundant, but copepod nauplii were not in evidence. A few Oikopleura made their appearance on the last grid in early February. Phytoplankton was generally scarce. By early March, the spring outburst was well under way; the plankton samples were characterized by the abundance and variety of both animal and plant species.

\section{DIET OF PLAICE LARVAE}

The quantity and nature of larval gut contents were recorded as part of the staging analysis. The results for both sets of grids are displayed in Table 2. In the absence of vulnerable animal food in January, the larvae ate plants only. The stomachs were never full nor the partly digested 'green food remains' (Lebour, I9I9) identifiable, although fragments of diatom tests could be recognized. The value of plant food for larval growth is a debatable point. If sufficiently abundant, the large thin-walled diatoms, e.g. Biddulphia and Coscinodiscus, may help sustain larvae in the transition stage; when scarce, as in January, the energy expended during foraging activity may not be balanced by the calorific value of the plants eaten.

The spring diatom outburst is closely followed by a marked increase in the zooplankton, particularly the appendicularian fraction. The important part Oikopleura plays in the diet of plaice larvae from the southern North Sea, has already been discussed by Shelbourne (1953). When the pelagic larval phase and the appendicularian outburst coincide, these small, soft-bodied, vulnerable creatures are eaten to the exclusion of other zooplankton species. In the March plankton patch, they were present in numbers sufficient to support a considerable population of larval plaice, and, as will be seen later, to have a measurable effect on physical condition in the transition stage.

The feeding analysis for March is expressed graphically in Text-fig. 2. Larval feeding can start as early as the mid-yolk period, with diatoms the main food item until the end of the yolked stage, when appendicularians become important. The average larval mouth is probably too small to accept juvenile appendicularians before the transition stage is reached, even though the prey may be attacked during the yolk phase of the predator. Exclusive feeding on Oikopleura and Fritillaria continued throughout the subsequent pelagic life of the larva. The small proportion of stomachs containing mixed diatoms and appendicularians suggests that the change-over from plant to animal food is comparatively abrupt. 
TABLE 2. THE GUT CONTENTS OF PLAICE LARVAE FROM BOTH PLANKTON PATCHES

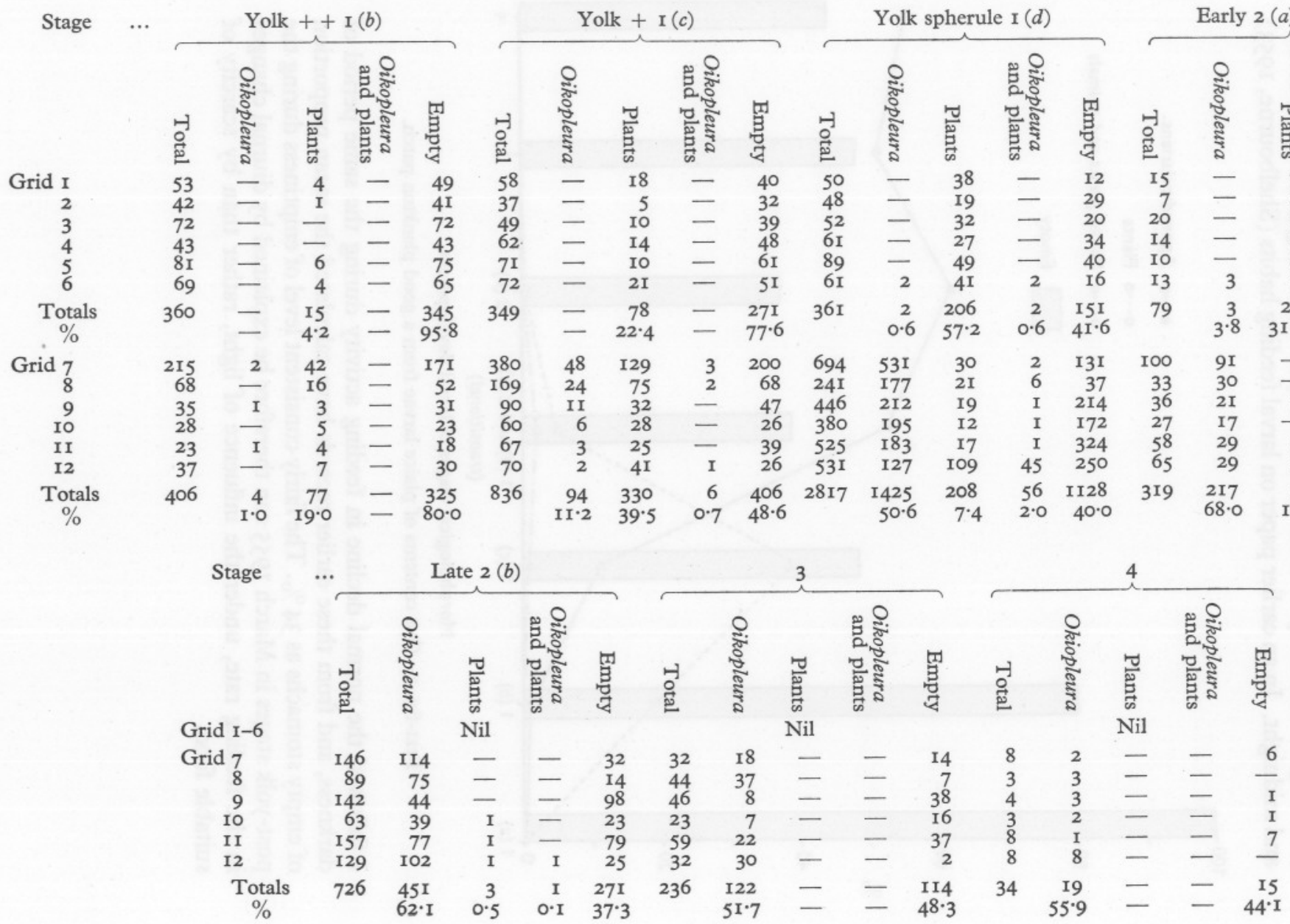


The superimposed histograms represent the proportion of empty stomachs found at each development stage. With the onset of feeding activity, the 'empty' proportion drops, to reach a steady level, about $40 \%$, for the postyolk stages. The samples used in this analysis were caught between $18.00 \mathrm{~h}$ and midnight. In an earlier paper on larval feeding habits (Shelbourne, 1953),

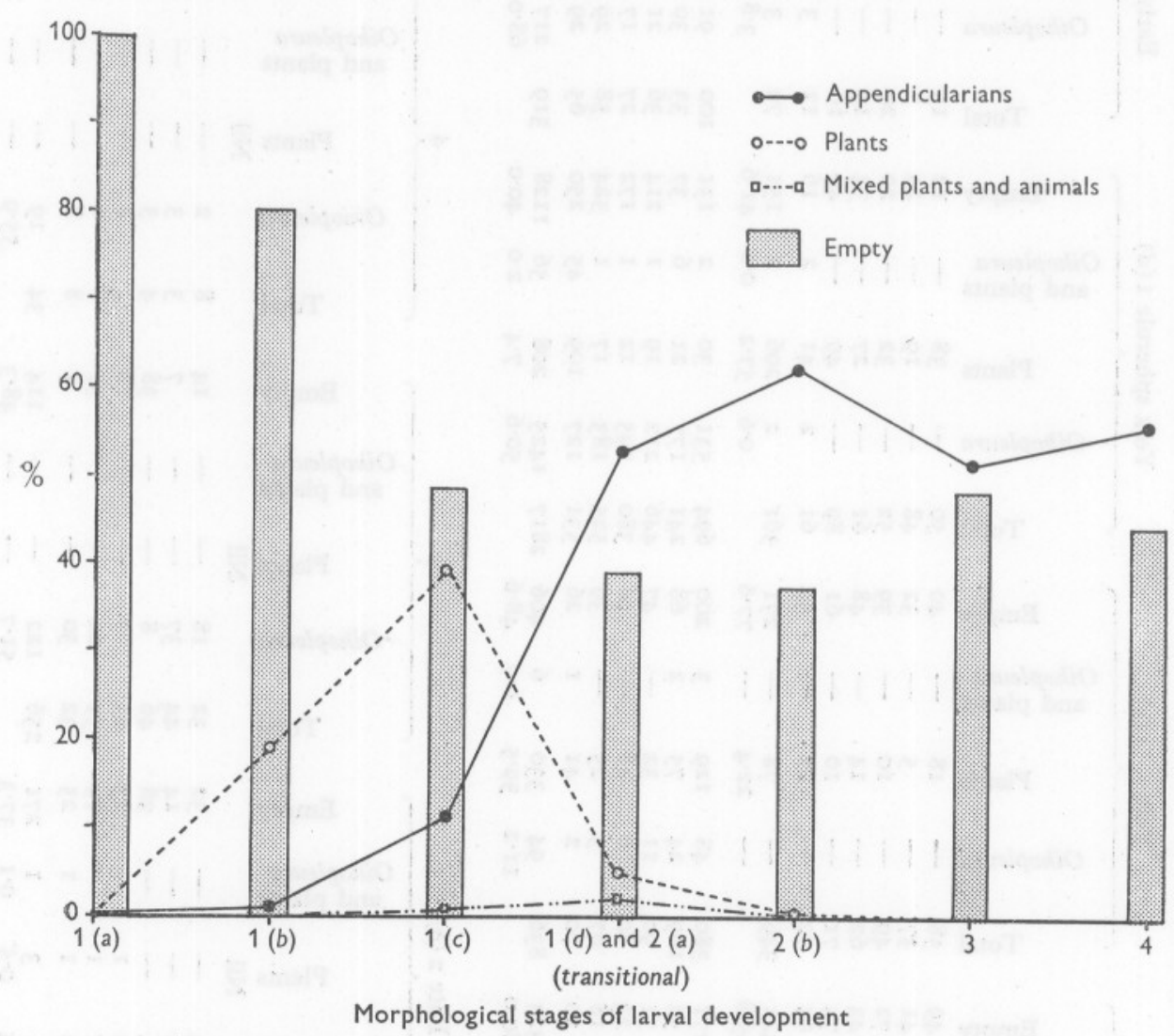

Text-fig. 2. Gut contents of plaice larvae from a good plankton patch.

I followed the normal decline in feeding activity during the same period of darkness, and from these earlier records have calculated the mean proportion of empty stomachs as $34 \%$. The fairly consistent level of emptiness during the post-yolk stages in March 1955 can therefore be explained by diurnal changes in the feeding rate, under the influence of light, rather than by scarcity of suitable food. 


\section{THE CONDITION OF TRANSITION STAGE LARVAE}

There was an association between food supply and the condition of the transition-stage plaice larvae. The problem of measuring larval condition was tackled by clearing and photographing five selected larvae (Pl. I, figs. 6-IO), ranging from very thin to very robust, enlarging the prints to microscope image size, and using these prints as visual standards in the subsequent catch analysis.

The guiding principle in assessing robustness was the relationship of the soft parts (gut and muscular axis) to the cartilaginous head structure. A thin larva thus appeared ill-proportioned, with a prominent head and a reduced trunk. A robust larva, on the other hand, had balanced proportions, with a heavily muscled trunk, conspicuous gut and a far less prominent head.

Although the standards were somewhat subjective, the difference between larval condition during the January and March grids, is obvious enough (Table 3). The figures for each grid are the adjusted totals from two hauls taken at each station on the grid. The adjustment factor (for volume of water filtered) was reached by dividing the mean flowmeter revolutions per grid by the actual flowmeter reading. In this way one can compare the larval numbers from each grid on a particular patch, and the adjusted total of larvae examined per patch does not differ markedly from the actual total. The mean flowmeter reading for patch I differed from that of patch 2 . The patch totals are not therefore adjusted to one another, but the condition compositions, dealing with proportions, are comparable. These proportions are expressed graphically in Text-fig. 3 .

Plaice larvae were not very abundant in January. Half those at the beginning of the transition stage (end of yolk stage) were in medium condition, the other half thin. There were no robust or very robust individuals. Larvae caught at the end of the transition stage showed a distinct trend towards thinness; yolk reserves had been exhausted and soft structures reduced during continued foraging activity.

In contrast, about half the early transitional larvae from the good plankton patch were robust or very robust, indicating profitable feeding before complete yolk loss. In the same good food supply, $90 \%$ of the larvae leaving the transition stage were robust or very robust; fatter than their slightly younger contemporaries, not thinner as in January. There were no late stage 2 larvae in the poor plankton patch. In reasonable conditions for survival, one would expect this group to have appeared in the plankton by early February, accompanied by definite signs of increasing robustness in the late transitional stage, a necessary prelude to the formation of the characteristic caudal cushion. In the absence of these signs I am tempted to conclude that starvation conditions prevailed in the January patch and that survival was low. Roughly one-third of the late stage 2 larvae caught in the second plankton 
TABLE 3. ADJUSTED NUMBERS PER DEVELOPMENT STAGE OF PLAICE LARVAE, WITH A CONDITION ANALYSIS OF THE TRANSITIONAL STAGES

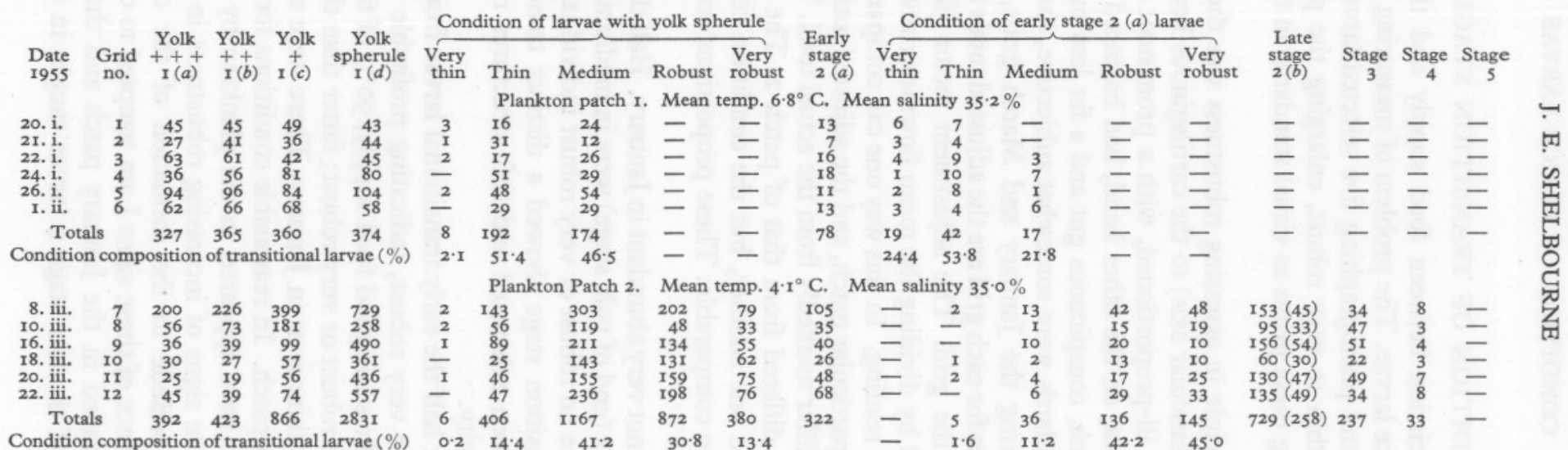

The bracketed numbers in the late stage $2(b)$ column represent larvae with a vestige of yolk still remaining in the body cavity. 
patch had a vestige of yolk in the body cavity, a sure sign of better conditions for larval growth and survival.

There can be no doubt that a strong correlation must exist between larval condition and food supply, when other environmental factors lie within the limits of tolerance. During sampling the only hydrographic observations made were of temperature and salinity. The mean sea temperature was

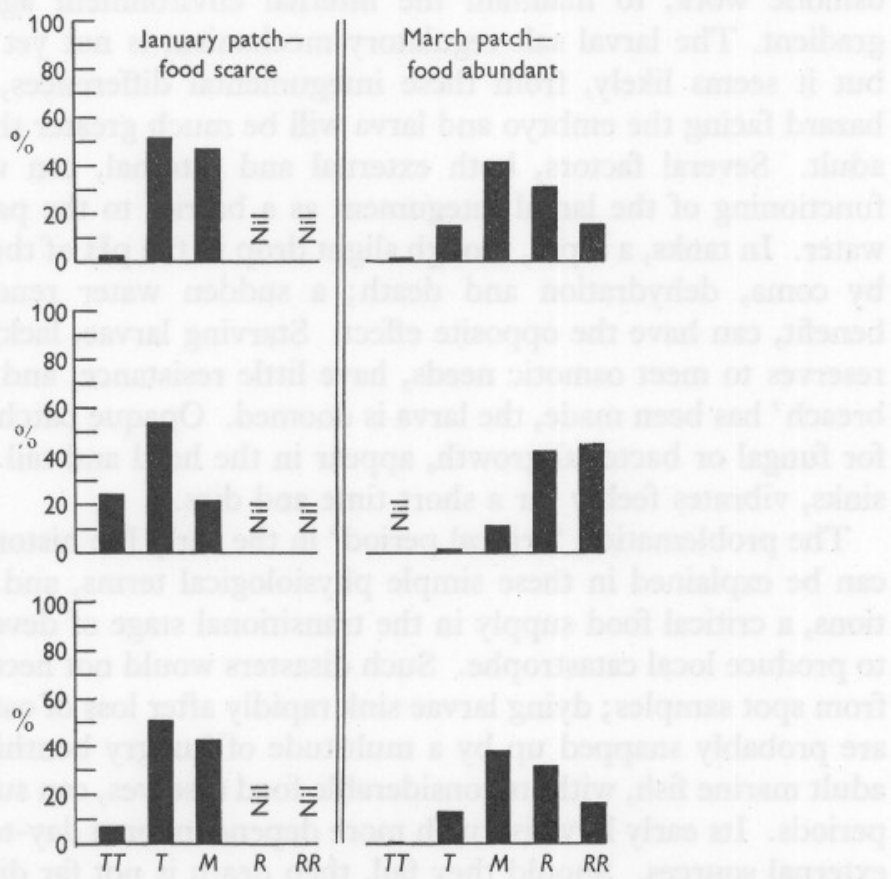

Text-fig. 3. Condition of transitional plaice larvae from good and bad plankton patches: $T T$, very thin; $T$, thin; $M$, medium; $R$, robust; $R R$, very robust. $U p p e r$, end of yolk stage, I $(d)$. Middle, beginning of post-yolk stage, $2(a)$. Lower, total transition stages, I $(d)+2(a)$.

probably more favourable in January $\left(6 \cdot 8^{\circ} \mathrm{C}\right)$, than in $\operatorname{March}\left(4 . \mathrm{I}^{\circ} \mathrm{C}\right)$, and there is no evidence from previous work that the small salinity difference between patches $(35 \cdot 2 \%: 35 \cdot 0 \%)$, could have such a profound effect on larval condition. However, there are growing indications of variable condition among developing plaice eggs caught at sea, and it is therefore unwise to assume that the January and March larvae of this investigation started life as embryos with uniform viabilities.

\section{DISCUSSION}

Many dangers beset the newly emerged marine fish larvae, not the least of which is osmosis. The mechanism of water and salt regulation is well known for the adult teleost, where its efficiency depends on the development of gills 
and chloride secreting cells, a completed circulatory system and a virtually water and salt proof skin (Krogh, I939). Only the gill and oral membranes are permeable. Cod and plaice larvae (representing the pelagic marine group) lack these essential structures up to the stage of complete yolk loss (Shelbourne, 1956). The integument is extremely thin over the whole of its surface, and a considerable amount of energy must be expended, in the form of osmotic work, to maintain the internal environment against the osmotic gradient. The larval salt regulatory mechanism is not yet fully understood, but it seems likely, from these integumental differences, that the osmotic hazard facing the embryo and larva will be much greater than that facing the adult. Several factors, both external and internal, can upset the efficient functioning of the larval integument as a barrier to the passage of salts and water. In tanks, a rapid, though slight drop in the $\mathrm{pH}$ of the water is followed by coma, dehydration and death; a sudden water renewal, intended to benefit, can have the opposite effect. Starving larvae, lacking sufficient food reserves to meet osmotic needs, have little resistance, and once an 'osmotic breach' has been made, the larva is doomed. Opaque patches, often mistaken for fungal or bacterial growth, appear in the head and tail regions; the larva sinks, vibrates feebly for a short time and dies.

The problematical 'critical period' in the early life history of marine fishes can be explained in these simple physiological terms, and in natural conditions, a critical food supply in the transitional stage of development, is likely to produce local catastrophe. Such disasters would not necessarily be evident from spot samples; dying larvae sink rapidly after loss of osmotic control, and are probably snapped up by a multitude of hungry benthic scavengers. An adult marine fish, with its considerable food reserves, can survive lengthy lean periods. Its early larva is much more dependent on a day-to-day supply from external sources. Should they fail, then death is not far distant.

Throughout a spawning period, in seas characterized by very uneven plankton distribution in time and space, it is reasonable to suppose that the fates of larval populations vary considerably, from local catastrophe in food conditions below subsistence level, to local prosperity where plankton is rich. These variations would inevitably be masked in the mean mortality curve for a large area. Given moderate weather, plankton patches would seem to be better suited to investigations on the 'critical period' in the life history of fish larvae, than vast spawning areas.

\section{SUMMARY}

In January and March, during the 1955 plaice spawning season, plankton samples were collected with a Heligoland larva net at stations on a grid around a floating radio buoy in the southern North Sea. There was a decided scarcity of suitable food for plaice larvae in the January patch, and this famine was 
reflected in the deteriorating physical condition of those larvae caught at the transition stage of development, when yolk reserves were becoming exhausted and an adequate external food supply essential. By March, the spring plankton outburst was in full swing. The condition of transitional larvae improved in this good food patch. Feeding started about the mid-yolk phase, mainly on plants. By the time most of the yolk had been resorbed, the appendicularians Oikopleura and Fritillaria had become the principal food items, and remained so throughout pelagic larval life.

Accurate mortality estimates during transient phases of development, depend largely on an understanding of the way in which the feeding rate affects the progress of larval development at a given temperature. Without this knowledge, the present data cannot be used to calculate mortality rates in the two plankton patches, but there are indications that in January, food was too scarce to support the growth and continued survival of the larval population, whereas in March, sufficient food was available for growth in the transitional stage, thus increasing the prospects of post-yolk survival.

There is reason to suppose that in local starvation conditions, larval control over their own internal salt balance would be greatly reduced, by lack of energy reserves for osmotic work at the thin integument. Failing a rapid improvement in the food situation, death must inevitably follow, and such local catastrophes would be hidden in the mortality curves derived from surveys over vast spawning areas.

\section{REFERENCES}

AHLSTROM, E. H., 1954. Distribution and abundance of egg and larval populations of the Pacific sardine. Fish. Bull., U.S., Vol. 56, No. 93, pp. 83-I40.

Apstern, C., I909. Die Bestimmung des Alters pelagisch lebender Fischeier. Mitt. dtsch. SeefischVer., Bd. 25, pp. 364-73.

AURICH, H. J., I94I. Die Verbreitung der pelagischen Fischbrut in der südlichen Nordsee während der Frühjahrsfarten 1926-1937. Helgoländ. wiss. Meeresunters., Bd. 2, Heft 2, pp. I83-225.

BRIDGER, J. P., I956. On day and night variation in catches of fish larvae. F. Cons. int. Explor. Mer, Vol. 22, No. I, pp. 42-57.

DANNEvig, H., I897. On the rearing of the larval and post-larval stages of the plaice and other flat-fishes. Rep. Fish. Bd Scot., I5th Year (1896), pt. III, pp. I75-93.

HJORT, J., I9I4. Fluctuations in the great fisheries of northern Europe viewed in the light of biological research. Rapp. Cons. Explor. Mer, Vol. 20, 288 pp.

1926. Fluctuations in the year classes of important food fishes. F. Cons. int. Explor. Mer, Vol. I, No. I, pp. 5-38.

JoHANSEN, A. C., 1927. On the fluctuations in the quantity of young fry among plaice and certain other species of fishes and causes of same. Rep. Danish biol. Sta., Year 1927, Vol. 33, pp. 5-16.

Krogh, A., 1939. Osmotic Regulation in Aquatic Animals, 242 pp. Cambridge University Press.

Lebour, M. V., 1919. The food of young fish. F. mar. biol. Ass. U.K., Vol. I2, pp. $26 \mathrm{I}-324$. 
MARR, J. C., I956. The 'critical period' in the early life history of marine fishes. f. Cons. int. Explor. Mer, Vol. 21, No. 2, pp. 160-70.

ReIBISCH, J., 1902. Über den Einfluss der Temperatur auf die Entwicklung von Fischeiern. Wiss. Meeresuntersuch., Abt. Kiel, Bd. 6, pp. 213-31.

Rollefsen, G., 1930. Observations on cod eggs. Rapp. Cons. Explor. Mer, Vol. 65, pp. $3 \mathrm{I}-4$.

SetTe, O. E., 1943. Biology of the Atlantic mackerel (Scomber scombrus) of North America. Part I: early life history, including the growth, drift and mortality of the egg and larval populations. Fish. Bull., U.S., Vol. 50, No. 38, pp. I49-237.

SETTE, O. E. \& AHLSTROM, E. H., I948. Estimations of abundance of the eggs of the Pacific pilchard (Sardinops caerulea) off Southern California during 1940 and 1941. f. mar. Res., Vol. 7, No. 3, pp. $51 \mathrm{I}-42$.

Silliman, R. P., 1943. Thermal and diurnal changes in the vertical distribution of eggs and larvae of the pilchard (Sardinops caerulea). F. mar. Res., Vol. 5, No. 2, pp. II 8-30.

Simpson, A. C., I951. The fecundity of the plaice. Fish. Invest., Lond., Ser. 2, Vol. I7, No. 5,27 pp.

ShelbourNe, J. E., I953. The feeding habits of plaice post-larvae in the Southern Bight. F. mar. biol. Ass. U.K., Vol. 32, pp. 149-59.

- 1956. The effect of water conservation on the structure of marine fish embryos and larvae. F. mar. biol. Ass. U.K., Vol. 35, pp. 275-86.

Soleim, P. A., 1940. Sildelarvene på vårsildefeltet. (En foreløbig meddelelse.) Fiskeridir. Skr. Havundersok., Bd. 6, No. 4, pp. 39-55.

- 1942. Arsaker til rike og fattige årganger av sild. Fiskeridir. Skr. Havundersøk., Bd. 7, No. 2, 39 pp.

Sund, O., 1924. Snow and survival of cod fry. Nature, Lond., Vol. I13, No. 2831, pp. 163-4.

\section{EXPLANATION OF PLATE I}

Development stages of plaice larvae, after Simpson (left). Fig. I. Stage I (6.0 mm). Fig. 2. Stage $2(7.6 \mathrm{~mm})$. Fig. 3. Stage $3(9.2 \mathrm{~mm})$. Fig. 4. Stage $4(12.6 \mathrm{~mm})$. Fig. 5. Stage 5 $(12 \cdot 2 \mathrm{~mm})$. Condition standards of transitional plaice larvae (right). Fig. 6. Very thin $(6 \cdot 1 \mathrm{~mm})$. Fig. 7. Thin $(6 \cdot 3 \mathrm{~mm})$. Fig. 8. Medium $(6 \cdot 9 \mathrm{~mm})$. Fig. 9. Robust $(6.8 \mathrm{~mm})$. Fig. Io. Very robust $(7 \cdot 5 \mathrm{~mm})$. 
J. MAR. BIOL. Ass. U.K., 36 (3)

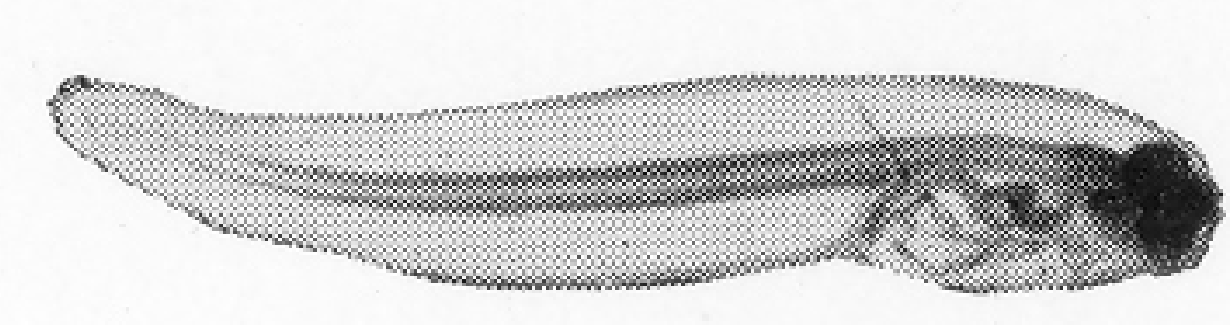

1

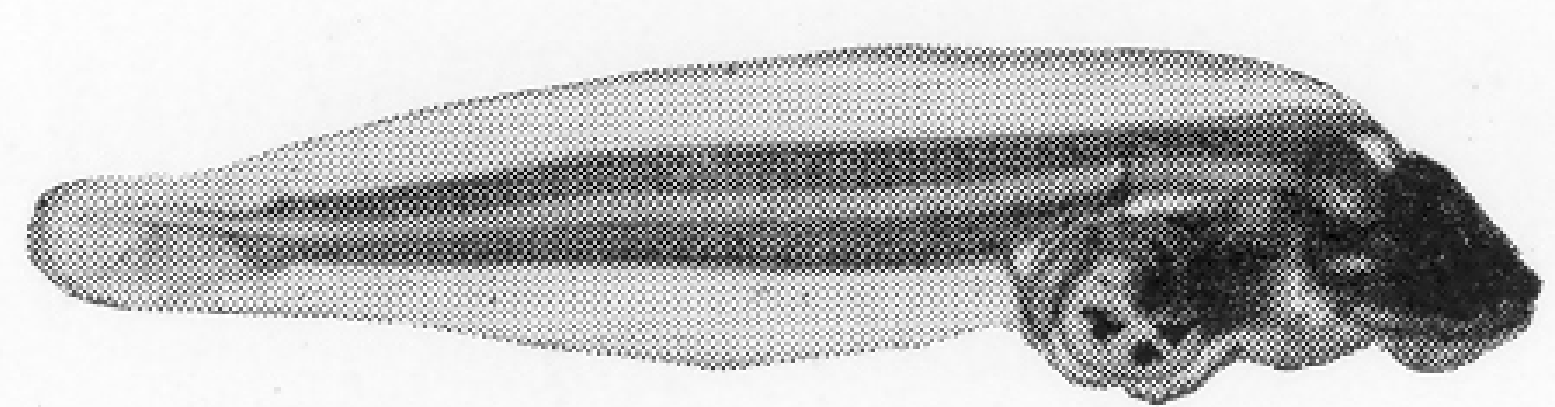

2

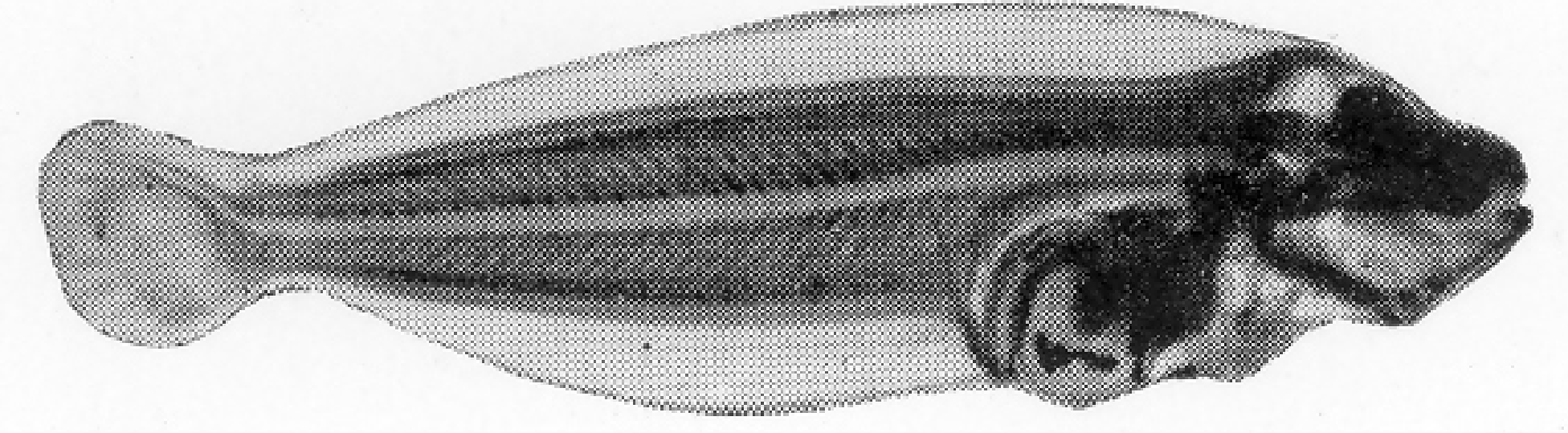

3
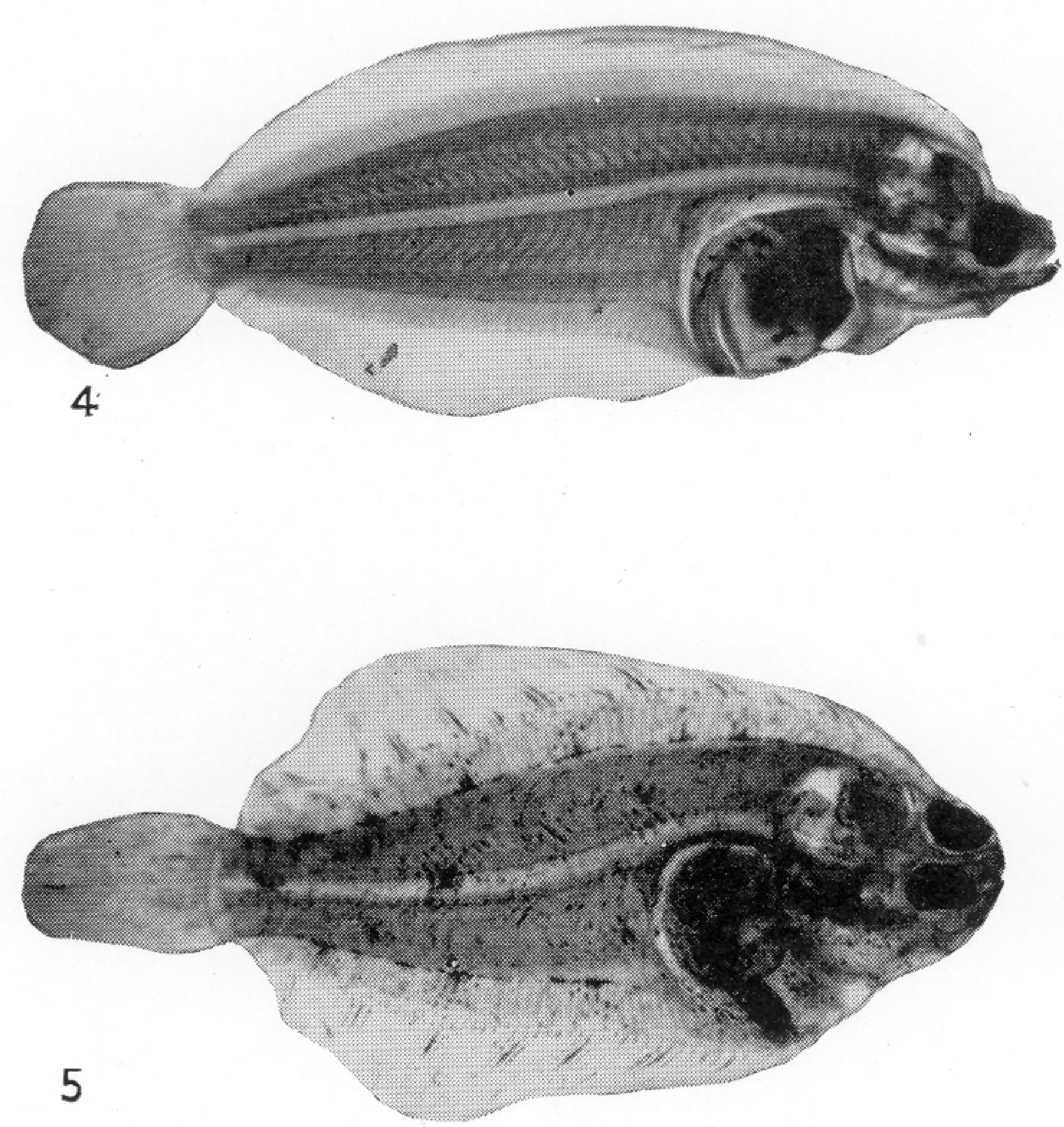

SHELBOURNE. PLATE I
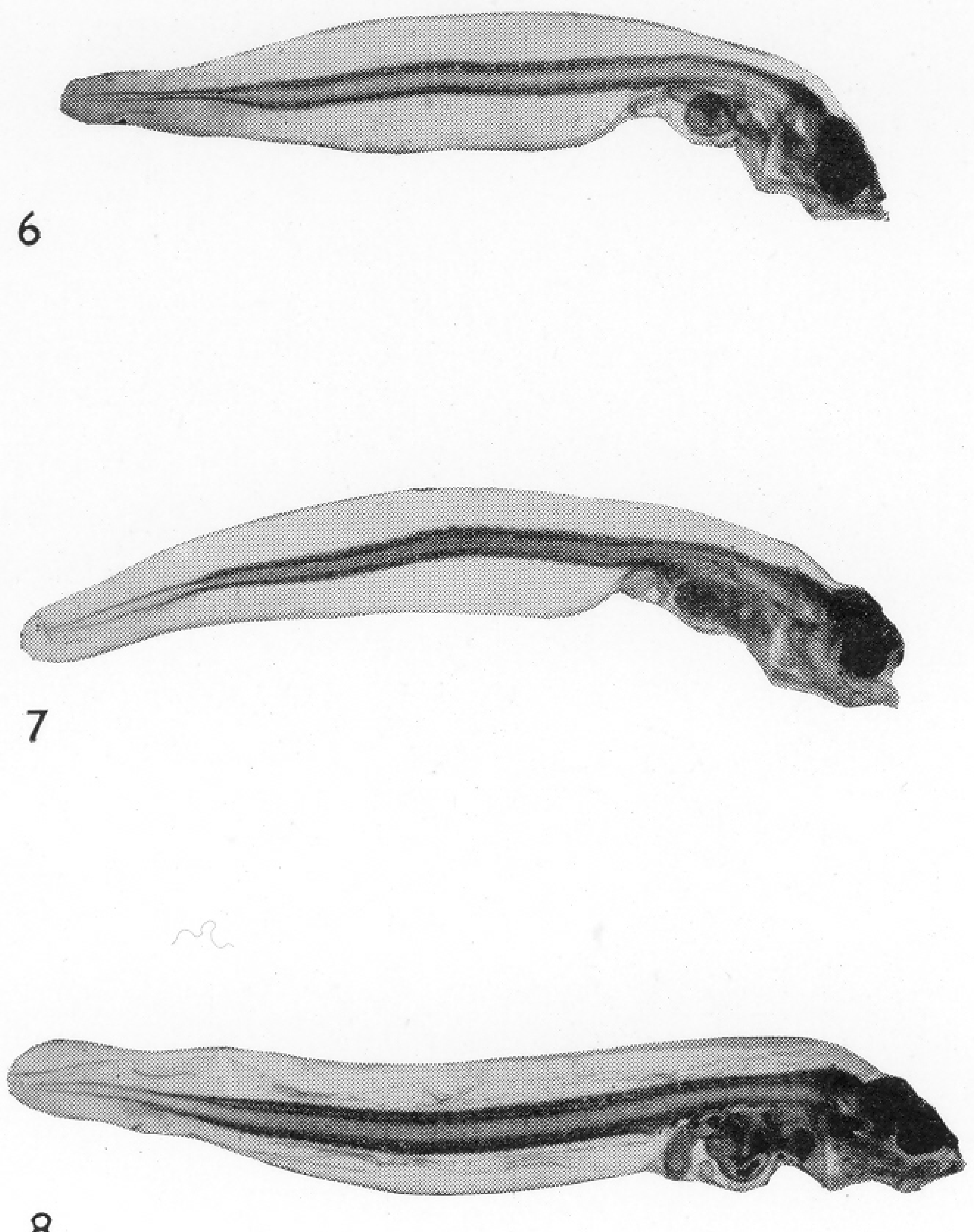

8
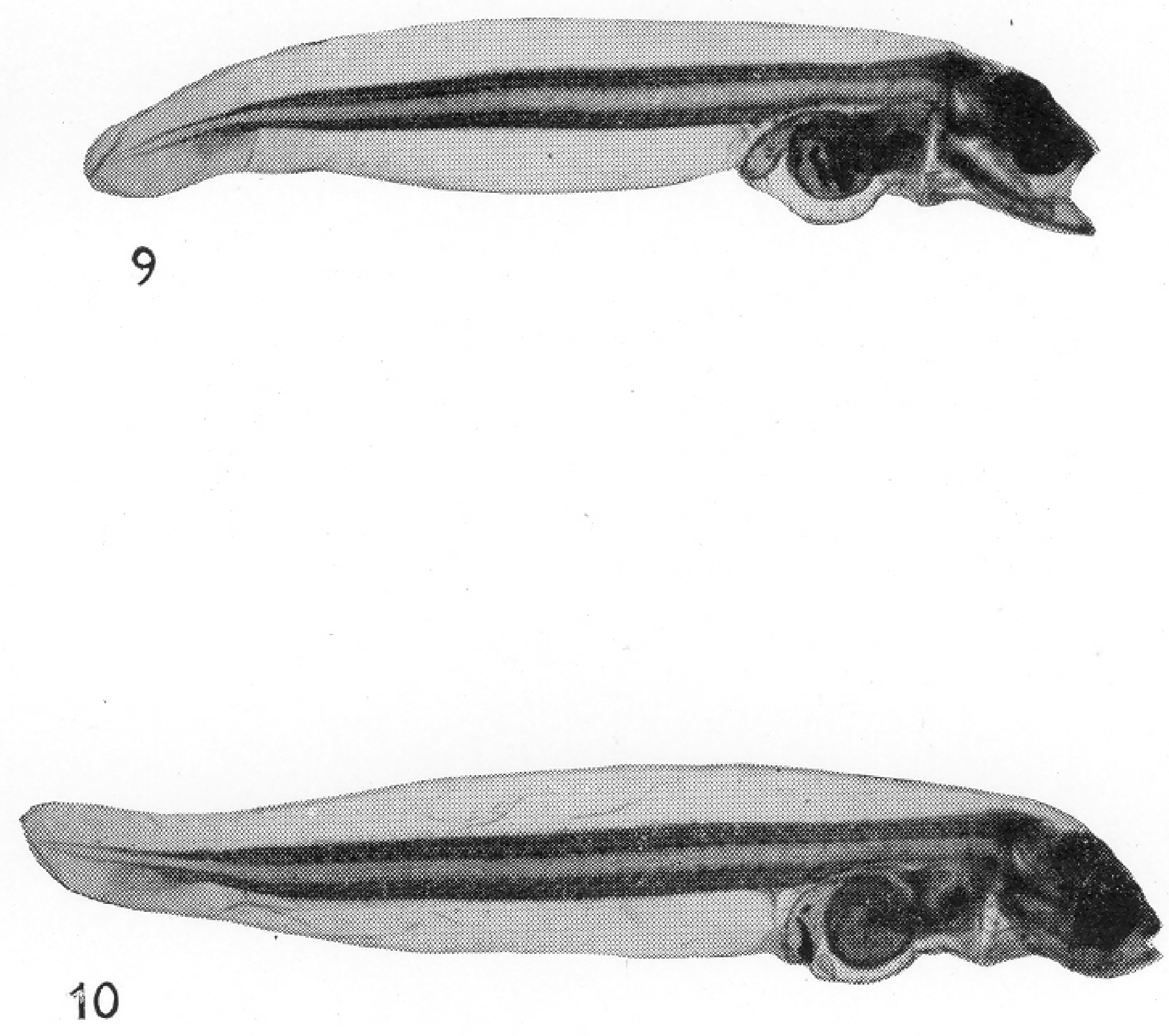

(Facing p. 552) 